\title{
Negotiation Aid System For Promotion of Distributed Generation and Renewables
}

\author{
Vladimiro Miranda, Cláudio Monteiro and I.J.Ramirez-Rosado
}

\begin{abstract}
This paper describes a new concept of a Negotiation Aid System, developed over a GIS (Geographic Information System) and designed to facilitate reaching compromises among agents such as investors, environmental groups and governmental agencies, when deciding the location and sizing of new renewable energy sources in a region. The core model of an Actor is similar to a Fuzzy Inference System of the Takagi-Sugeno type, built from a definition of preferences and levels of acceptability. An outranking method is employed to define geographical places of less conflict among the several Actors negotiating. An application to the region of La Rioja, in Spain, is described.
\end{abstract}

Index Terms: New Renewable Energies, Decision Aid, Negotiation Aid, Fuzzy Sets, Geographical Information Systems

\section{INTRODUCTION}

$\mathrm{T}_{\mathrm{t}}$ The development of distributed generation has been conditioned in the European Union by constraints that limit the success of governamental incentives, aimed at increasing the penetration of renewables in the EU power generation portfolio, having in mind the Kyoto protocol. These incentives have several forms, from subsidies to the construction of new generation facilities to guaranteed "green" prices and tariffs for energy from renewables including avoided costs for $\mathrm{CO}_{2}$ emmissions. Therefore, investors put a heavy pressure in searching for places where to build new renewable plants and where to connect them to the grid with the purpose of selling energy.

One source of constraints to the widespread use of wind generation derives from supra-national, national or local regulations, creating protected zones, natural or national parks, areas of protected bio-diversity or ecologically protected, besides zones close to buildings, airports, etc. or related with the military or possibility of radar confusion.

Another source of constraints derives from the opposition of environmental organizations, who locally object to renewables while at national level continue to claim for their use. Therefore, Government Energy Directorates or Energy Agencies need to have at hand a comprehensive methodology to try

V. Miranda is with INESC Porto - Institute of Engineering in Sy stems and Computers at Porto, Portugal, and with FEUP - Faculty of Engineering of the University of Porto, Portugal (vmiranda@inescporto.pt)

N. Fonseca is with the Power Systems Unit of INESC Porto, Portugal (email: nfonseca@power.inescn.pt)

I.J.Ramirez-Rosado is with the University of La Rioja, Spain (email: ignacio.ramirez@die.unirioja.es) to conciliate the interests of different agents (investors, environmentalists, state agents) in order to organize regional plans for the development of distributed renewable generation [1].

This paper presents one Negotiation Aid platform for such purpose [2][3][4]. It is built over a GIS - Geographical Information System[5], and it allows the identification, over a map of a region, of the zones or areas where the conflicting interests of several actors may best be conciliated. The model goes through two steps: a decision phase for each Actor in the negotiation process and a conciliation phase among all the Actors; the process may iterate, guided by a broker agent and, given certain circumstances, it may even use techniques of training and automatic learning to capture the essence of the preferences of each Actor. The core of the model is a decision rule for each Actor in the form of a Takagi-Sugeno Fuzzy Inference System, which provides as output an aceptance or tolerance index about the location of wind generation at each cell in a GIS map.

The work described has been applied in a joint project developed for the region of La Rioja, Spain, by INESC Porto and the University of La Rioja, and some results are displayed in the paper, under the form of maps and graphs. The model is a revised and corrected version of the one described in a previous publication [6].

\section{BUILDING THE CONCEPT}

A Negotiation Aid System (NAS) is different from a Decision Aid System (DAS) in the following basic aspects:

- a NAS targets a set of agents or Actors, instead of a single Decision Maker, as in the case of a DAS

- in a NAS, each Actor defines his own interests and objectives and evaluates alternatives based on attributes and criteria, independently of the attitude of the other agents

- the criteria adopted by an Actor are not necessarily the same nor in the same number as the criteria adopted by any other agent.

This means that one cannot directly transport for a NAS environment the techniques usually employed in DAS where a single Decision Maker is present. For instance, if the actors do not share the same criteria, it is not possible to define a set of alternatives with the property of Pareto Optimality.

To build a NAS, we have therefore proceeded to take two successive steps: 1) to develop a model for each Actor; and 2) to apply a model for the interaction among actors. 


\section{FIS MODEL FOR AN INDIVIDUAL ACTOR}

\section{A. General model}

An Actor evaluates an alternative in an attribute $\mathrm{k}$, giving value $C_{k}(x)$ with $x \in D_{k}$, where $\mathbf{D}_{k}$ is a domain of definition for $\mathrm{x}$; then, $\mathrm{C}_{\mathrm{k}}(\mathrm{O})$ is defined in a domain $\mathbf{C D}_{\mathrm{k}}$. If $\mathrm{x}$ is a cell in a map and $\mathrm{k}$ is an attribute such as "distance to an urban center", then $\mathrm{C}_{\mathrm{k}}(\mathrm{x})$ is a concrete distance value.

We now define a membership function $\mu_{\mathrm{k}}^{\prime}: \mathbf{C D}_{\mathrm{k}} \rightarrow[0,1]$ expressing "preference" for a solution taking values in $\mathbf{C D}_{\mathrm{k}}$. This has an obvious parallel with an utility function in utility theory. In linguistic terms, this function $\mu_{\mathrm{k}}$ represents the fuzzy set "preferred attribute values under criterion k". The following composition gives the fuzzy set "preferred solutions under criterion k":

$$
\mu_{\mathrm{k}}: \mathbf{D}_{\mathrm{k}} \rightarrow[0,1], \quad \mu_{\mathrm{k}}=\mu_{\mathrm{k}}{ }^{\circ} \mathrm{C}_{\mathrm{k}}
$$

In a GIS environment, the domain of decision $\mathbf{D}_{\mathrm{k}}$ is discrete: it is constituted by the set of cells representing the region at a given level of geographical resolution. The membership functions $\mu_{\mathrm{k}}$ cannot easily be defined by an analytical expression. However, it is possible to define a set of ranges for the values of $\mathrm{C}_{\mathrm{k}}(\mathrm{x})$, with $\mathrm{x}$ being any cell in a map in a GIS, and allow the Actor to define values of preference, in the interval $[0,1]$, which become a discrete representation of the membership function $\mu_{\mathrm{k}}$

For instance, imagine that, for some reason, an Actor prefers places located at the distance of $1 \mathrm{~km}$ from an urban center. Each cell in the map could be classified as

\begin{tabular}{|l|c|}
\hline Distance & Preference index $\left(\mu_{\mathrm{k}}\right)$ \\
\hline $0-200 \mathrm{~m}$ & 0.1 \\
\hline $200-500 \mathrm{~m}$ & 0.4 \\
\hline $500-900 \mathrm{~m}$ & 0.7 \\
\hline $900-1200 \mathrm{~m}$ & 0.95 \\
\hline $1200-1600 \mathrm{~m}$ & 0.3 \\
\hline$>1600 \mathrm{~m}$ & 0.1 \\
\hline
\end{tabular}

When taking in consideration more than one criterion at the same time, the relative importance of each criterion is, in many cases, translatable into a "weight" representing attractiveness. This means that, in some way, the Actor is able to rank criteria according to importance. The Actor must consider the distinct degrees of "attraction" or "rejection" that a solution has over him when considered under different lights (criteria). This "attraction effect" is represented, in our model, by applying a modifier to the preference value expressed by $\mu_{\mathrm{k}}$ in criterion $\mathrm{k}$.

The application of a modifier is done by a composition of functions. If the membership function of the modifier applied to criterion $\mathrm{k}$ is $\mathrm{m}_{\mathrm{k}}:[0,1] \rightarrow[0,1]$, then we have the preference, modified by the attractiveness, as a function $\mathrm{g}_{\mathrm{k}}$

$$
\mathrm{g}_{\mathrm{k}}: \mathbf{D}_{\mathrm{k}} \rightarrow[0,1], \quad \mathrm{g}_{\mathrm{k}}=\mathrm{m}_{\mathrm{k}}^{\circ} \mu_{\mathrm{k}}
$$

This membership function $\mathrm{g}_{\mathrm{k}}$ is associated with a fuzzy set $\mathbf{G}_{\mathrm{k}}$ denoting the "weighted preference" of a solution under criterion $\mathrm{k}$.

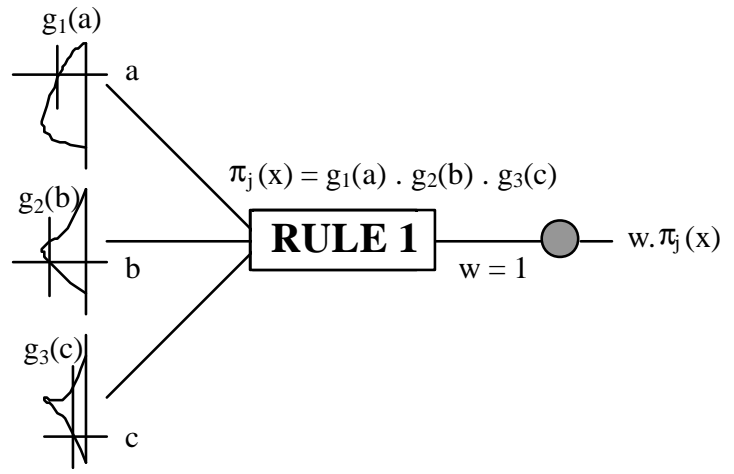

Figure 1 - TS FIS with a single rule: a cell $\mathrm{x}$ in a map with three values $(a, b, c)$ in three criteria, giving as output a tolerance index for $\mathrm{x}$.

An Actor must however consider at the same time several criteria "weighted" by their relative attractiveness. One has therefore the following decision rule (example):

IF a solution is

Far from urban centers (very important)

AND

Close to existing power lines (important)

AND

Has high wind availability (extremely important)

THEN the solution is accepted (tolerance index = 1)

Our decision simulation model is like a 0-order Fuzzy Inference System of the Takagi-Sugeno type (TS FIS), with a single rule, having fuzzy inputs and a crisp output (see Figure 1).

The antecedent part of the rule defines for Actor $\mathrm{j}$ an aggregated fuzzy set $\Pi_{j}$ with membership function $\pi_{\mathrm{j}}$ representing his "preference for an alternative". We have, for the nj criteria being considered by Actor $\mathrm{j}$

$$
\Pi_{\mathrm{j}}=\mathrm{G}_{1} \cap \mathrm{G}_{2} \cap \ldots \cap \mathrm{G}_{\mathrm{nj}}
$$

One must select a t-norm to represent this intersection of fuzzy sets. An adequate choice must be a compensatory operator, so that a good preference induced by a criterion is not totally erased by a less good evaluation in another criterion. Therefore, we have rejected the $\min$ operator and have adopted the product operator for the intersection of fuzzy sets, as it is usual in TS FIS. Then,

$$
\pi_{\mathrm{j}}(\mathrm{x})=\mathrm{g}_{1}(\mathrm{x}) \cdot \mathrm{g}_{2}(\mathrm{x}) \ldots \mathrm{g}_{\mathrm{nj}}(\mathrm{x})
$$

The membership value $\pi_{\mathrm{j}}$ may be interpreted as a "tolerance index". It is the activation strength of the rule, and because the weight of the rule is defined as being 1, the output of the rule is exactly $\pi_{\mathrm{j}}$ (in a TS FIS with $\mathrm{n}$ rules, the output would be the sum, for all the $\mathrm{n}$ rules, of the product of the activation strength of each rule by its weight).

\section{B. Attractiveness of criteria}

The complement to "being acceptable" is "being rejectable". We may define these concepts by fuzzy sets, constituting a fuzzy partition, with $\mathrm{m}$ as the membership function for "acceptable" and $\mathrm{r}$ for "rejectable". We have

$$
\mathrm{m}(\mathrm{x})+\mathrm{r}(\mathrm{x})=1, \quad \forall \mathrm{x}
$$

The solutions form 2 fuzzy clusters. A membership value of $\mathrm{m}=\mathrm{r}=0.5$ denotes a case of indifference. Values below 0.5 in 
the set "acceptable" denote opposition, while values above 0.5 express acceptability. A value of zero (0) expresses a veto. Of course, it is always possible to implement a veto threshold in a practical application, by setting all values below such threshold as equal to zero.

We have adopted the following membership function to represent the set "acceptable":

$$
\mathrm{m}_{\mathrm{w}}(\mathrm{p})=\left(1+\mathrm{e}^{10 \mathrm{w}(1-2 \mathrm{p})}\right)^{-1}
$$

A sketch of this function and its complement $r_{w}(p)$ is represented in Figure 1. The shape of this function depends on a parameter $\mathrm{w}$ as seen in Figure 2.

Through the manipulation of "w", an Actor may place more or less weight in the acceptability of a criterion. Instead of defining a discrete set of modifiers, we allow the Actor to select a value for $\mathrm{w}$ and build his own modifiers adequate to express the relative importance that he associates with each criterion.

The model allows veto and absolute preference thresholds:

Veto threshold: $v t=0.5-\frac{1}{10 \mathrm{w}}$

Absolute preference threshold: ap $=0.5-\frac{1}{10 \mathrm{w}}$

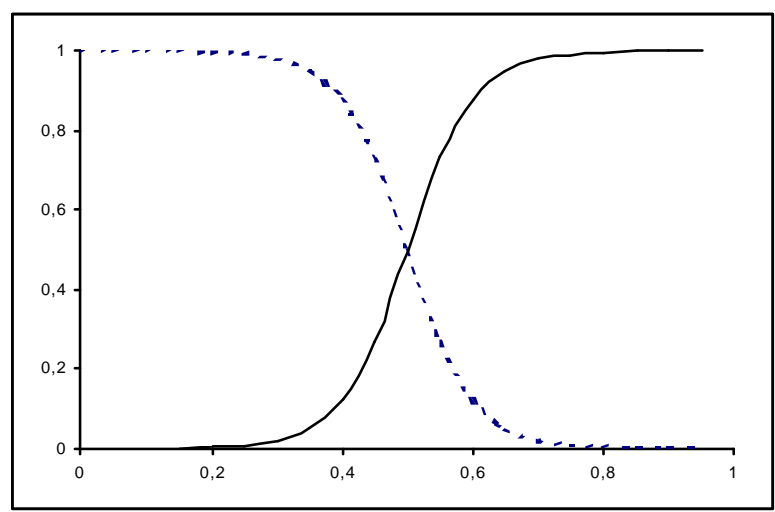

Figure 2 - Membership function for the modifier "acceptable" (full line) and "rejectable" (dashed line)

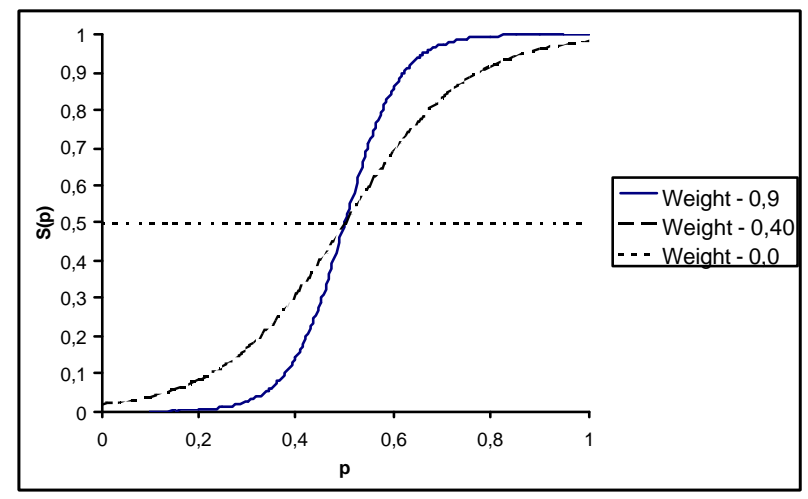

Figure 3 - Variation of the modifier membership function with parameter $w$

\section{Ranking locations in GIS}

Having calculated $\pi_{\mathrm{j}}$ for all cells in a map, one may proceed to establish a ranking by counting, for each cell, how many are considered preferable to it or how many outrank it in the preference concept of Actor j. If Map is the set of cells,

$$
\text { OutrankA }_{j}(x)=\operatorname{Count}\left\{\pi_{\mathrm{j}}(\mathrm{y})>\pi_{\mathrm{j}}(\mathrm{x}), \forall \mathrm{y} \in \mathrm{Map}\right\}
$$

This allows a (geo)graphic displaying of the aggregated preference, usually translated into colored maps that illustrate the preference structure for the particular Actor $\mathrm{j}$.

\section{Training}

This FIS model for an Actor has also another potential: it may serve to capture, from experience, the true nature of the relative importance of the criteria. In fact, if an Actor is able to rank solutions (or map cells) according to his aggregated preference, then a training procedure may be applied, using backpropagation, to adjust the parameter $\mathrm{w}$ of the functions $\mathrm{m}()$. One must have available a set with target outputs $\mathrm{T}$ and will minimize the mean square error of the summation, for all cells in the training set,

$$
\min \phi=\sum\left(\mathrm{T}_{\mathrm{j}}-\pi_{\mathrm{j}}\right)^{2}
$$

A chain rule will give

$$
\frac{\partial \phi}{\partial w_{k j}}=\frac{\partial \phi}{\partial \pi_{j}} \frac{\partial \pi_{j}}{\partial g_{k j}} \frac{\partial g_{k j}}{\partial m_{k j}} \frac{\partial m_{k j}}{\partial w_{k j}}
$$

and gradient iterations will correct the parameter $\mathrm{w}_{\mathrm{kj}}$ controlled by a learning parameter $\eta$, such as

$$
\mathrm{w}_{\mathrm{kj}}{ }^{\text {(new) }}=\mathrm{w}_{\mathrm{kj}}{ }^{(\text {old })}+\eta \frac{\partial \phi}{\partial \mathrm{w}_{\mathrm{kj}}}
$$

as in any usual backpropagation scheme in neuro-fuzzy models.

\section{MODEL FOR SEVERAL ACTORS}

\section{A. Renormalization}

A comparison of the strengths of preferences for several actors cannot be done directly from comparing membership values $\pi_{\mathrm{j}}$ for each Actor $\mathrm{j}$ in a set of $\mathrm{T}$ actors $(\mathrm{j}=1$ to $\mathrm{T})$ : the application of the product t-norm leads to smaller and smaller $\pi_{j}$ values with increasing number of criteria and it is likely that each Actor considers a different number of criteria. Therefore, we must apply a process of renormalization of the rule output values in order to make the preferences of all actors comparable.

Admit that each Actor $\mathrm{j}$ is represented by a single-rule TS FIS producing $\pi_{\mathrm{j}}$ as output. The renormalized preference set $\bar{\Pi}_{\mathrm{j}}$ is determined by transforming the membership function $\pi_{\mathrm{j}}$ into

$$
\bar{\pi}_{\mathrm{j}}(\mathrm{x})=\sqrt[\mathrm{nj}]{\pi_{\mathrm{j}}(\mathrm{x})}
$$

recalling that $\mathrm{nj}$ is the number of criteria that Actor $\mathrm{j}$ takes in consideration. 
The renormalization process does not affect the relation of order within the fuzzy set, relative to membership values; therefore, rankings of solutions are not changed.

\section{B. Compromise ranking}

To allow a (geo)graphic display of the areas of compromise among any subset of Actors, usually translated into colored maps, one counts, for each cell in the map, how many cells are simultaneously preferred to it by the Actors. For instance, for Actors $\mathrm{j}$ and $\mathrm{k}$

$\operatorname{OutrkC}_{\mathrm{jk}}(\mathrm{x})=\operatorname{Count}\left\{\pi_{\mathrm{j}}(\mathrm{y})>\pi_{\mathrm{j}}(\mathrm{x}) \wedge \pi_{\mathrm{k}}(\mathrm{y})>\pi_{\mathrm{k}}(\mathrm{x}), \forall \mathrm{y} \in \operatorname{Map}\right\}$

Notice that for this process one does not need the renormalization operation. Maps based on this ranking will help to identify areas of lesser and of greater conflict.

\section{Maps of equal preference}

With the help of the renormalized preferences, it is also possible to identify areas of the map where several actors have the same "preference strength", and find map intersections among Actors for these same value levels.

\section{The negotiation process}

All the maps mentioned above have informative value. In a negotiation process, it is important that each Actor becomes aware of the way others see the problem and of his own and each other's margins of flexibility.

The negotiation process must be conducted by a broker or facilitator, who will help the Actors in becoming aware of the consequences of slightly changing criteria or preferences. This is a phase of possible intense simulation, from which Actors will progressively become aware of the feasible negotiation margins and the resulting "geographical trade-offs". As a Negotiation Aid System, one does not expect the system to point out any solution.

\section{APPLICATION}

This Negotiation Aid model has been applied to the region of La Rioja, Spain. The objective is to identify areas in the territory where the potential for conflict is low. This identification may help the local Autonomic Government and its Agencies for Economic Development in defining policies for the use of renewables and for licensing new generation facilities.

The problem under modeling has been the definition of locations to allow investment in new wind parks.

Investors may express their preferences for locations near the existing electric grid, or with the highest economic efficiency in generating electricity (other GIS applications calculate the equivalent marginal value of generated electricity in $€ / \mathrm{kWh}$ for each cell in the map).

Environmentalists will express their opposition to places located in the path of bird migration or too close to villages or invading protected zones.

The government will try to impose its own criteria on the use of the land, or to enforce protection plans defined at national or European Union level.

The following figures illustrate some of the results obtained. The system was developed with ArcInfo and ArcView tools and is one of the modules of a much more complex set of applications.

The database of the GIS has been filled up with data from La Rioja and modules defining the economic efficiency of renewable energies have been developed; these modules may be used to help defining some of the data necessary to be considered by the Negotiation Aid System.

The simulations represent a Negotiation process between a Group of Investors in Wind Parks and an Environmentally Oriented Group.
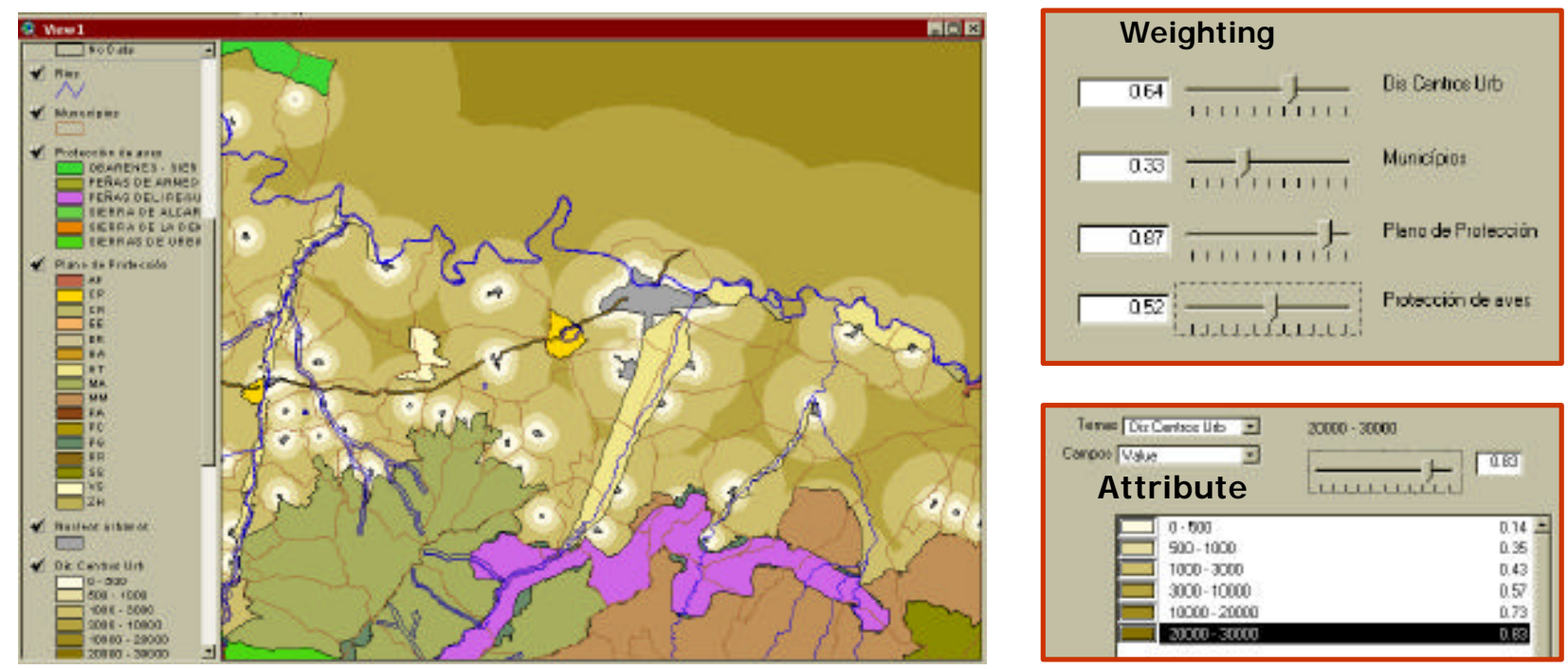

Figure 4 - City of Logroño and surrounding area: map identifying coverages related with distinct criteria and interface allowing an Actor to define his preferences and weights in several criteria (the criteria in the figure are: distance to urban centers, municipalities, nature protection plan, bird protection - output from the actual application). 


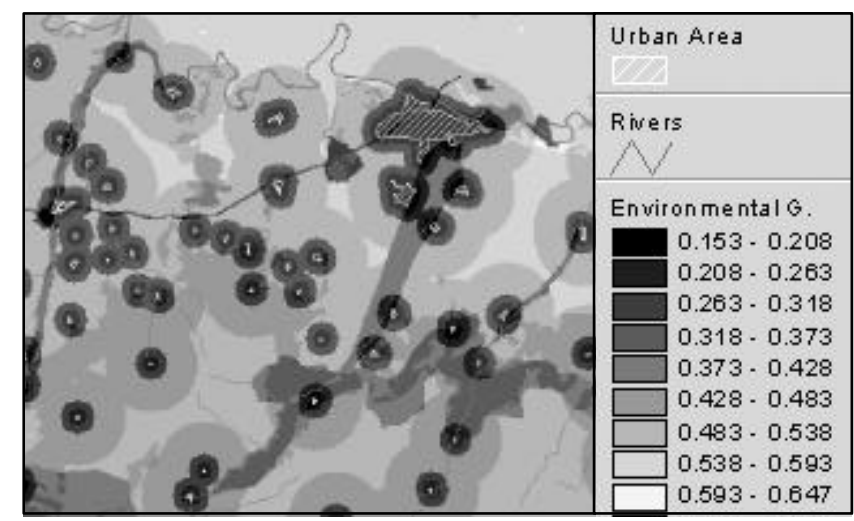

Figure 5 - Tolerance index maps for the environment interest group. The dark zones represent sites with lower tolerance. We can observe less tolerable zones near urban centers and in some environmental protected areas.

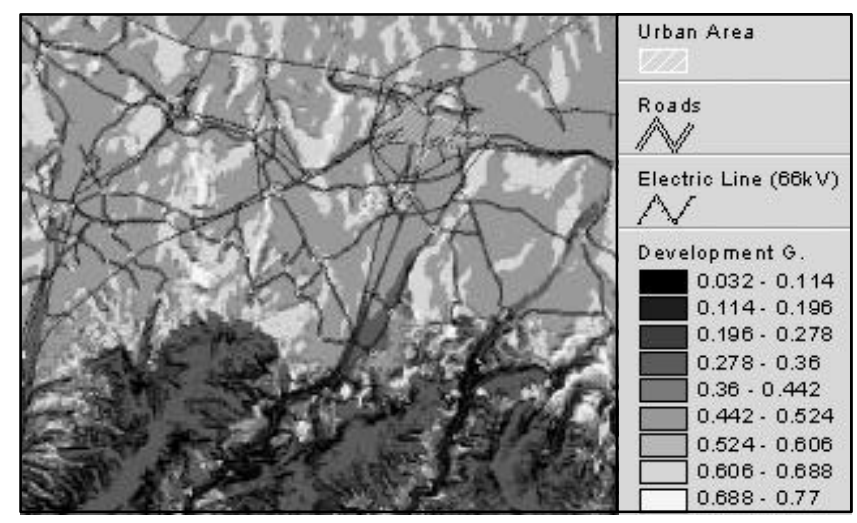

Figure 6 - Tolerance index maps for the wind farm development interest group. The dark zones represent sites with lower tolerance. We can observe better interest areas in some locations with high potential resources and technically acceptable sites.

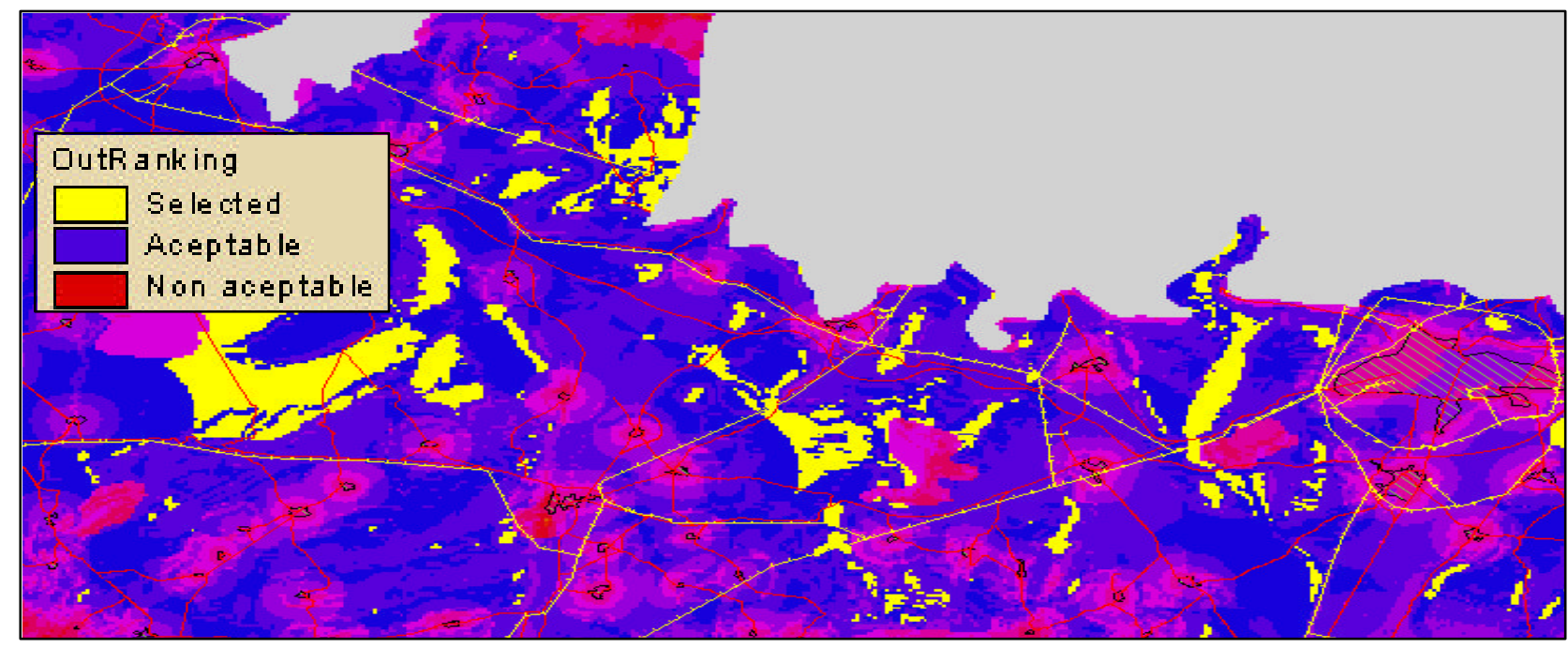

Figure 7 - Region in La Rioja. Simulation of a conciliation process between two Actors, representing a Group of Investors and an Environmentally Concerned Group: identification of areas of coincidence of choice and areas of no agreement, for the development of wind parks of $220 \mathrm{MW}$.

\section{CONCLUSIONS}

This paper offers the following contributions:

a) a model that allows the comparison of preferences among several Actors in a negotiation framework

b) a fuzzy set model that allows each Actor to express his own criteria independently of the criteria defined by the other actors;

c) a model that allows the identification of alternatives with the smallest possible potential for conflict among Actors;

d) the implementation of the model over a GIS platform to help negotiations in order to explore new renewable energy resources;

e) an implementation that allows Actors to experiment with the importance of their criteria and to test distinct scenarios, in order to discover compromise solutions

f) the application of such model to the Autonomic Region of La Rioja, in Spain.

The development of Negotiation Aid Systems is one important step into generating coherent and feasible plans for using the energy resources of a region, given that there is a liberalization of the generation activity, promoting the increase of dispersed generation. 
This pressure for building new facilities, owned and operated by private entities, leads to conflicts that may even paralyze the predicted and desired development.

A Negotiation Aid System that allows flexibility during the negotiation process or allows the simulation of such a process is, on the contrary, a tool to promote development within the limits of respect for the interests of all actors in the society.

\section{AKNOWLEDGMENT}

The project ENERGIS has been supported by the research project 2FD97-1514 sponsored by the Spanish Authorities and European Union funds, as well as by the projects HP19990005, ACPI2000/09 and API01/B31.

It also received contributions from the project INTELECTOOL, sponsored by the Portuguese Government (FCT).

The authors wish to express their gratitude to the developing team, namely to Eduardo García-Garrido, Luis Alfredo Fernández-Jiménez, Pedro J. Zorzano-Santamaría, Enrique Zorzano-Alba, Pedro Lara-Santillan, Montserrat MendozaVillena, Miguel Sousa, Carina Morais, Arturo MartínezFernández and all the others that allowed the success of this project.

\section{REFERENCES}

[1] Permitting of Wind Energy Facilities - A Handbook, Report prepared by NWCC Siting Subcommittee, March 1998

[2] Carver, S.J.. "Integrating Multi-Criteria Evaluation With Geographical Information Systems" International Journal of Geographical Information Systems. 5(3):331-339, 1991

[3] Densham, P.J.. "Spatial Decision Support Systems". In D.J. Maguire, M.F. Goodchild, and D.W. Rhind, ed., Geographical Information Systems: Principles and Applications, 403-412, New York: John Wiley, 1991
[4] Olson, D.L.. "Decision Aids for Selection Problems". New York: Springer-Verlag., 1996

[5] Jankowski, P. 1995. "Integrating Geographical Information Sy stems And Multiple Criteria Decision-Making Methods". International Journal of Geographical Information Systems. 9(3):251-273, 1995

[6] Monteiro, C., Miranda, V., Ramirez-Rosado, I.J., "A Negotiation Aid System For The Development Of Distributed Renewable Generation", Proceedings of PSCC'02 - Power Systems Computation Conference, Sevilla, Spain, June 2002

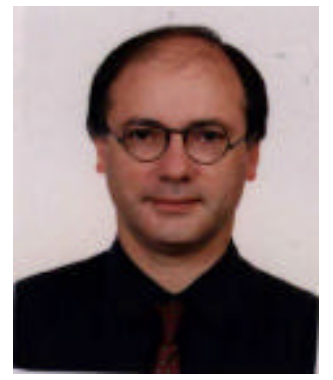

Vladimiro Miranda is Director of INESC Porto, Portugal, a non-for-profit private research and development institution. He is also with the Faculty of Engineering of the University of Porto (FEUP). His area of interest is the application of Computational Intelligence to Power Systems.

He has been responsible for many projects in the European union and other countries and he has authored a large number of papers in Planning and Operation, Fuzzy Sets and Evolutionary Computing applied to Power Systems.

Cláudio Monteiro is with INESC Porto as a Researcher and with FEUP as a lecturer. His area of interest is the application of GIS Geographical Information Systems to Power Systems and new Renewable Energies.

Ignacio J. Ramirez-Rosado is Full Professor of the Department of Electrical Engineering of the University of La Rioja (Spain). He has been responsible of several research projects in the Power Systems area, mainly in Networks Planning and Load Forecasting. His current interest areas are integrated electricity resources planning and operation, and applications of novel computational techniques and intelligent systems to electric power systems. 